\title{
Similarity between seed rain and neighbouring mature tree communities in an old-growth temperate forest
}

\author{
Yunyun Wang ${ }^{1} \cdot$ Jalene M. LaMontagne $^{2}$. \\ Fei Lin ${ }^{1} \cdot$ Zuoqiang Yuan $^{1} \cdot \mathrm{Ji} \mathrm{Ye}^{1} \cdot$ Xugao Wang $^{1}$. \\ Zhanqing Hao ${ }^{1}$
}

Received: 18 December 2017 / Accepted: 7 May 2018 / Published online: 24 September 2019

(C) The Author(s) 2019

\begin{abstract}
Seed distribution and deposition patterns around parent trees are strongly affected by functional traits and therefore influence the development of plant communities. To assess the limitations of seed dispersal and the extent to which diaspore and neighbouring parental traits explain seed rain, we used a 9-year seed data set based on 150 seed traps in a 25-ha area of a temperate forest in the Changbai Mountain. Among 480,598 seeds belonging to 12 families, 17 genera, and 26 species were identified, only $54 \%$ of the species with mature trees in the community were represented in seeds collected over the 9 years, indicating a limitation in seed dispersal. Understory species were most limited; overstory species were least limited. Species with wind-dispersed
\end{abstract}

Project funding: This paper is supported by National Key Research and Development Program of China (2016YFC0500300), National Natural Science Foundation of China (31570432, 31670632, 41671050), NSF Grant DEB1745496.

The online version is available at http://www.springerlink.com

Corresponding editor: Zhu Hong.

Electronic supplementary material The online version of this article (https://doi.org/10.1007/s11676-019-01027-3) contains supplementary material, which is available to authorized users.

Jalene M. LaMontagne

jlamont1@depaul.edu

Zhanqing Hao

hzq@iae.ac.cn

1 CAS Key Laboratory of Forest Ecology and Management, Institute of Applied Ecology, Chinese Academy of Sciences, Shenyang 110016, People's Republic of China

2 Department of Biological Sciences, DePaul University, Chicago, IL 60614, USA seed had the least limitation, while the lowest similarity in species richness was for animal-dispersed species followed by gravity-dispersed species; fleshy-fruited species had stronger dispersal limitations than dry-fruited species. Generalized linear mixed models showed that relative basal area had a significant positive effect on seed abundance in traps, while the contribution of diaspore traits was low for nearly all groups. These results suggest that tree traits had the strongest contribution to seed dispersal and deposition for all functional groups examined here. These findings strengthen the knowledge that tree traits are key in explaining seed deposition patterns, at least at the primary dispersal stage. This improved knowledge of sources of seeds that are dispersed could facilitate greater understanding of seedling and community dynamics in temperate forests.

Keywords Seed rain - Dispersal mechanisms - Tree traits $\cdot$ Basal area $\cdot$ Changbai mountain $\cdot$ Temperate forest

\section{Introduction}

The dispersal patterns of seeds influence the subsequent dynamics and structure of plant populations and forest communities (Nathan and Muller-Landau 2000; Dupré and Ehrlén 2002; Levine and Murrell 2003; Seidler and Plotkin 2006). Seed dispersal is the primary way that sessile plants colonize new habitats, reduce intra-specific competition, and escape from pathogens associated with the parent plants (Harms et al. 2000; Maron and Kauffman 2006; Jordano et al. 2011). Seed dispersal is a highly unpredictable process (Wenny 2001) that is affected by both the functional traits of plants (Dalling et al. 2002; Li et al. 2012) and characteristics of the surrounding vegetation (Augspurger et al. 2016). Knowledge of how the attributes of diaspores (the 
seed plus any additional tissues that assist dispersal), trees (e.g., height and fecundity), and community structure (e.g., dispersal mode and canopy layer), explain seed deposition patterns is still limited (Bleher and Böhning-Gaese 2001; Ghazoul 2005; Schurr et al. 2008; Thomson et al. 2011; but see Augspurger et al. 2016).

Diaspore traits (e.g., dispersal mode and fruit type) play important roles in determining seed dispersal and deposition patterns (Hardesty and Paker 2003; Muller-Landau et al. 2008; Li et al. 2012). Generally, the deposition patterns of animal-dispersed seeds are more variable and less predictable (due to animal handling and hoarding) than gravityand wind-dispersed seed governed by physics (Seidler and Plotkin 2006; Réjou-Méchain et al. 2011; Li et al. 2012; Beaudrot et al. 2013). The species composition of seeds deposited by gravity or dispersed by wind in an area better reflect local dispersal events, where most seeds fall beneath or are dispersed near parent plants, than species with animal-dispersed seeds/fruits (Janzen 1970; Nathan and MullerLandau 2000; Seidler and Plotkin 2006; Moran and Catterall 2010). In addition, the dispersal mode co-evolves with fruit type (Gautier-Hion et al. 1985). Species with fleshy fruit and heavier seeds tend to be animal-dispersed, while species with dry fruit and lighter seeds are dispersed by wind (Gautier-Hion et al. 1985; Lorts et al. 2008).

Seed dispersal and seed deposition patterns among species strongly depends on tree attributes (e.g., canopy layer and fecundity; Van Der Burgt 1997; Muller-Landau et al. 2008). Seed production is directly proportional to tree size (e.g., basal area; Greene and Johnson 1994). Generally, a large seed crop leads to greater variation in the height of seed release in the crown of trees compared to when seed crops are small (Nathan et al. 2002). Dispersal distance and clumping within seed shadows, a measure to quantify dispersal distance and area around isolated parents (Ribbens et al. 1994), generated by wind, vary markedly among species based on differences in tree height (Muller-Landau et al. 2008). For species with the same dispersal mode or similar seed mass, dispersal distance increases with tree height (Muller-Landau et al. 2008; Thomson et al. 2011). As a result, dispersal limitations are lower for trees in the overstory of temperate forests than for trees in the other canopy layers (Li et al 2012).

The objectives of this study were to examine variations in seed deposition patterns around neighbouring trees in a forest community comprised of different functional-trait groups and to determine the relative importance of diaspore and plant traits in explaining variations between functional groups. Using a 9-year data set for seed collected from 150 seed traps in a 25 -ha temperate forest dynamics plot in Northeast China, we compared species composition and abundance of the seed rain community with those of the neighbouring tree community. We asked: (1) To what extent does the species richness and abundance of the seed community resemble those of the neighbouring tree community? (2) How much do the specific functional traits (i.e., canopy layer, dispersal mode, and fruit type) differ in their effect on dispersal limitation? (3) Are diaspore traits or tree traits more powerful for explaining seed deposition patterns?

For each of these questions, we predicted that (1) the seed community would be similar to the neighbouring tree community in species richness and relative abundance in this temperate forest because, in addition to having strong dispersal limitations (Li et al. 2012), many species in temperate forests tend to be dispersed by wind (Wang et al. 2014). By contrast, in tropical forests, many trees belong to animaldispersed species (Jordano et al. 2003) whose seeds may be dispersed farther and to more unpredictable locations by animals (Wenny 2000; Ruxton and Schaefer 2012); (2) the correspondence between seed deposition and the surrounding tree community would be higher for overstory species than for the understory and midstory species and that winddispersed and gravity-dispersed species would be more similar than species dispersed by animals. Similarly, species with dry fruit are expected to be closer to neighbouring trees than species with fleshy fruit; (3) tree functional traits would be more likely than diaspore traits to explain seed deposition patterns, as seen previously in a study of wind-dispersed species (Augspurger et al. 2016). Identifying the contribution of functional traits of trees to seed dispersal is essential for understanding the link between dispersal and seedling recruitment, which affects parental fitness and population and community structure.

\section{Materials and methods}

\section{Study site}

The $500 \times 500 \mathrm{~m}$ Changbai Mountain forest dynamic plot (CBS) was established in 2004 in a stand of about 300-yearold mixed broad-leaved-Korean pine forest in Northeast China. The CBS plot is relatively flat with elevations from 791.8 to $809.5 \mathrm{~m}$ a.s.l. Climate is characterized as moist temperate monsoon, with a mean annual temperature of 2.8 ${ }^{\circ} \mathrm{C}$, and mean annual precipitation of approximately 700 $\mathrm{mm}$, most of which occurs from June to September (Yang and Li 1985).

All free-standing stems at least $1 \mathrm{~cm}$ in diameter at breast height (DBH, $1.3 \mathrm{~m}$ above the ground) were mapped in 2004 and identified to species following standard field protocol (Condit 1998); a total of 34,926 individuals belonging to 51 species were enumerated in a recensus in 2009. The average stand density in 2009 was 1397 trees ha ${ }^{-1}$, and the mean basal area $44.52 \mathrm{~m}^{2} \mathrm{ha}^{-1}$ (Wang et al. 2011). The canopy composition of species with 
basal area of more than $1 \mathrm{~m}^{2} \mathrm{ha}^{-1}$ accounted for $95.3 \%$ of the total basal area. Six species represented $90 \%$ of the total basal area: Tilia amurensis Rupr., Pinus koraiensis Siebold \& Zucc., Quercus mongolica Fisch. ex Ledeb., Fraxinus mandschurica Rupr., Acer mono Maxim., and Ulmus davidiana Planch. var. japonica (Rehd.) Nakai. These are hereafter referred to as the dominant species.

\section{Tree traits}

Diameter at breast height (DBH) in 2009 was used as a proxy for the maturity of trees during the study period because there was no information on the reproductive status of each tree for each year during 2006-2015. The threshold size for maturity of each species was based on the literature (Zhou and Chen 2001) and direct field observations. A total of 48 species were included in the tree community (Table S1), except for Lonicera ruprechtiana Regel, Lonicera subhispida Nakai and Deutzia parviflora Bge. var. amurensis Regel.

Each species was classified based on (1) canopy position (overstory, midstory, or understory; Zhou and Chen 2001; Wang et al. 2010); (2) dispersal mode (wind, gravity, or animal; Zhou and Chen 2001); and (3) fruit type (dry or fleshy; Zhou and Chen 2001).

\section{Seed rain collection}

In 2005, 150 seed traps were established throughout the CBS plot in a relatively regular spacing in a grid of $25 \times 25$ subplots of $20 \mathrm{~m} \times 20 \mathrm{~m}$ (Zhang et al. 2008; Li et al. 2012) (Fig. $\mathrm{S} 1$ in Appendix). Each trap was $0.5 \mathrm{~m}^{2}$ located in the centre of each $400-\mathrm{m}^{2}$ subplot. A combination of typical grids and circular plots was used to arrange seed traps to limit the maximum distance to $31 \mathrm{~m}$ between trees and the nearest seed trap (Li et al. 2012).

Seed rain was collected twice a month from May to December and once a month from January to April from July 2006 to August 2015. All seeds, fruits, seed-bearing fruit fragments, flowers, capsules and other reproductive parts that fell into seed traps were identified to species and recorded (Muller-Landau et al. 2008). Hereafter, only seeds are included when referring to "seeds". Because long-term data are needed to obtain reliable seed estimates (Clark et al. 1999), all seed data during the study period were used to compare the structure of the seed rain with that of the neighbouring full-grown trees. To ensure data reliability, species with fewer than 200 total seeds and from no more than five seed traps across the 9 years were excluded; consequently, 15 species were included in the data analyses for each group (Table 1). Seed mass (1000 seed weight) was obtained from collections in the field and from the literature (Zhou and Chen 2001).

Table 1 Taxa represented in seed rain in rank order over 9 years in Changbai Mountain forest dynamic plot

\begin{tabular}{|c|c|c|c|c|c|c|c|c|}
\hline Species & Family & $\mathrm{IV}^{\mathrm{a}}$ & SeedN ${ }^{b}$ & TA & $\operatorname{Trap}^{c}$ & CL & $\mathrm{DM}$ & FT \\
\hline Tilia amurensis Rupr. & Malvaceae & 0.117 & 282,115 & 2504 & 68 & Overstory & Gravity & Fleshy \\
\hline Fraxinus mandschurica Rupr. & Oleaceae & 0.095 & 108,065 & 667 & 87 & Overstory & Wind & Fleshy \\
\hline $\begin{array}{l}\text { Ulmus davidiana Planch. var. japonica } \\
\text { (Rehd.) Nakai }\end{array}$ & Ulmaceae & 0.037 & 35,277 & 1065 & 56 & Overstory & Wind & Dry-indehiscent \\
\hline Acer mono Maxim. & Sapindaceae & 0.089 & 19,517 & 6479 & 61 & Midstory & Wind & Dry-indehiscent \\
\hline Acer pseudo-sieboldianum Komarov & Sapindaceae & 0.069 & 15,250 & 4690 & 71 & Midstory & Wind & Dry-indehiscent \\
\hline Quercus mongolica Fisch. ex Ledeb. & Fagaceae & 0.069 & 7792 & 905 & 62 & Overstory & Animal & Dry-indehiscent \\
\hline Betula platyphylla Suk. & Betulaceae & 0.006 & 3100 & 92 & 11 & Midstory & Wind & Dry-indehiscent \\
\hline Acer barbinerve Maxim. & Sapindaceae & 0.052 & 3094 & 3562 & 71 & Understory & Wind & Dry-indehiscent \\
\hline Pinus koraiensis Siebold \& Zucc. & Pinaceae & 0.152 & 2327 & 2351 & 1 & Overstory & Animal & Dry-indehiscent \\
\hline Acer tegmentosum Maxim. & Sapindaceae & 0.022 & 1431 & 687 & 52 & Midstory & Wind & Dry-indehiscent \\
\hline Tilia mandshurica Rupr. et Maxim. & Malvaceae & 0.008 & 579 & 336 & 11 & Overstory & Gravity & Fleshy \\
\hline Acer mandshuricum Maxim. & Sapindaceae & 0.010 & 502 & 233 & 23 & Midstory & Wind & Dry-indehiscent \\
\hline Populus koreana & Salicaceae & 0.001 & 414 & 5 & 1 & Overstory & Wind & Dry-dehiscent \\
\hline Maackia amurensis & Fabaceae & 0.020 & 311 & 642 & 38 & Midstory & Gravity & Dry-dehiscent \\
\hline Acer triflorum Kom. & Sapindaceae & 0.010 & 261 & 267 & 25 & Midstory & Wind & Dry-indehiscent \\
\hline
\end{tabular}

Importance values (IVs) are based on relative abundance, relative basal area, and relative frequency of tree neighbours within $20 \mathrm{~m}$ from focal traps

Tree abundance means the total number of trees $(\mathrm{dhb}>1 \mathrm{~cm})$ in the plot

$T A$ tree abundance, $C L$ canopy layer, $D M$ dispersal mode, $F T$ fruit type

${ }^{a}$ IV is relative abundance + relative basal area + relative frequency. ${ }^{b}$ SeedN is number of seeds. ${ }^{\text {cTap }}$ is percentage of traps $(n=126)$ around which at least one mature individual of this species occurred 


\section{Data analyses}

The best measure to compare the species composition of seeds with that of parent trees in a community is based on the Jaccard similarity coefficient for species composition between seed rain and neighbouring trees within radii of 1-30 $\mathrm{m}$ in steps of $1 \mathrm{~m}$ (Li et al. 2012) using tree location on the plot map. There were similar Jaccard values for both the 15- and 20-m circles (Fig. S2 in Appendix) using the seed collection for all 26 species. Pearson's correlations were calculated between seed abundance and importance value (IV) per species. IV is the sum of abundance, relative basal area (hereafter, RBA) and frequency of tree neighbours per species within circles centered on each focal trap (Hardesty and Parker 2003) for both distances. The RBA of conspecific neighbouring trees was calculated using basal areas modified by the distance between neighbours and the focal species within each trap. That is, the basal area of each conspecific tree within a 20-m circle from the focal seed species in each trap was divided by the distance of each tree from the focal seed trap (Bai et al. 2012), and then these modified RBAs for each species were summarized as:

$R_{\mathrm{BA}}=\sum_{\mathrm{i}}^{N} B_{\mathrm{A} i} /$ DISTANCE $_{i}$

where $R_{\mathrm{BA}}$ is relative basal area; $B_{\mathrm{A} i}$ is basal area for mature tree $i$; DISTANCE $E_{i}$ is the distance between neighbours and the tree $i$ of focal species within each trap. Data were excluded from the 24 traps within $20 \mathrm{~m}$ of the edge of the plot because of the possible influence from uncensused trees outside the plot (Muller-Landau et al. 2008). The Pearson correlation for 20-m circles $(r=0.901)$ was higher than for 15 -m circles $(r=0.835)$. Thus, all further data analyses were conducted using $20-\mathrm{m}$ circles.

\section{Jaccard similarity coefficient}

We calculated the Jaccard similarity coefficient between observed seed collection and the neighbouring mature-tree community for each trait (canopy layer, dispersal mode, and fruit type) because all the individuals occurring at seed traps were expected to be from neighbouring individuals of the respective species within radii of $20 \mathrm{~m}$. Species richness of the seed community (the shared species) was first calculated using the samples from each seed trap and for surrounding trees in the $20 \mathrm{~m}$ area around every focal trap. The trap-level species richness of neighbours was then divided by species richness of the seed community to calculate the percentage of similarity (Jaccard index), and the means were calculated across all seed traps for each trait.

\section{Model construction of comparison between seed and tree communities}

Generalized linear mixed models (GLMMs) were used to test the relative effects of diaspore characteristics and tree traits on seed deposition, focusing on seed primary dispersal, that is, seed abundance in seed traps (Blume et al. 2007). The differences between levels of the three functional groups, (1) canopy layer, (2) dispersal mode, (3) fruit type, were determined using separate GLMM analyses for each group. There was only one species in the understory; therefore, this level was excluded in model construction.

The GLMM included a Poisson-distributed response variable, seed abundance of all species falling into each seed trap. Independent biotic variables included seed dispersal mode, seed mass, fruit type, neighbour-tree traits (canopy layer, Mdst.seed.adult $=$ mean distance between seed rain in focal trap and neighbouring mature trees, RBA, neighbouring tree abundance). Topography affects seed distribution by influencing the parent plant's spatial distribution and seed dispersal (Shen et al. 2004; Schurr et al. 2008); therefore, elevation was used as an explanatory variable in the models. Elevation of each $20 \times 20 \mathrm{~m}$ quadrat was obtained from the four corners across the plot using an electronic distance measuring device (Condit 1998). The average of the four values was taken, and the models corrected for over-dispersion (Nakagawa and Schielzeth 2013).

Canopy layer models (overstory, midstory) included dispersal mode, fruit type, seed mass, Mdst.seed.mature, RBA, mature tree abundance and elevation. Fruit type was excluded from the overstory and midstory models because, in the first, fruit type was confounded with dispersal mode while the second had only dry-fruited species. Models can be applied only to factors with two or more levels. Dispersal mode models, wind, gravity, animal, included all the previous terms and the canopy layer in the wind model, but not the animal model because this group had only overstory and not the gravity model because fruit type was highly correlated with canopy layer. The fruit type model for dry fruit included all the terms in the canopy layer model and the canopy layer itself, but for fleshy-fruited species, dispersal mode, canopy layer, and elevation were excluded because these three factors had only one level for this group.

The values of the continuous explanatory variables were standardized by subtracting the mean value of the variable and dividing by one standard deviation (Schielzeth 2010). For continuous variables, pairwise correlations showed that there was no multicollinearity based on a threshold of 0.7 (Dormann et al. 2013). The Pearson $\chi^{2}$ test in the R package vcd was used to compute correlations among categorical 
variables. The mean and range of several continuous variables used in the analyses are listed in Table S2.

To identify the influence of the various diaspore characteristics and tree traits on seed abundance for each functional group, we used information-theoretic model averaging (Burnham and Anderson 2004). The goal was not only to find a single best model but the terms having the highest association with the observed seed deposition patterns. This approach avoids some pitfalls of conventional stepwise regression analyses, which can inflate type I error rates, and potential model selection uncertainty associated with the use of single statistical models (Burnham and Anderson 2004; Whittingham et al. 2006). For each group, all possible model combinations of independent variables were run, and the unconditional model-averaged regression coefficients were calculated based on models with the sum of the weights of the top models of no less than 0.90 . The odds ratio, a measure of association between the presence and/or absence of a property, (see McHugh 2009), was used to measure the significance of each variable in the models.

All statistics were calculated in R 3.2.2 (R Core Team 2015). The GLMMs were carried out in the R package lme4 (Bates et al. 2011), and Akaike information criterion (AIC) model fitting and model-averaged regression coefficients were done in the R package MuMIn (Bartón 2016).

\section{Results}

During the 9-year study, 480,598 seeds were collected from the traps, representing 12 families, 17 genera, and 26 species. Mean $( \pm \mathrm{SD})$ seed species richness among traps was $8.75 \pm 1.5$ (range: $5-14$ ) and mean seed abundance was 3204 \pm 1781 (range: 457-11,189) (Fig. S1 in Appendix). The 26 species represented in the seed rain consisted of $95.4 \%$ of the tree species in the community based on IV. The rank order by either seed count or tree IV showed steep negative exponential distributions with a large proportion of common species. The six most abundant species in seed number (T. amurensis, F. mandschurica, U. davidiana var. japonica, Acer mono, Acer pseudo-sieboldianum, Q. mongolica) consisted of $97.4 \%(468,016)$ of the total seeds (Table 1$)$.

For species composition at the community level, 26 species accounted for $54 \%$ of the total forest species (48) during the 9-year study (Table S1), with a maximum median Jaccard coefficient of approximately 0.5 (Fig. S2 in Appendix). Among functional groups, the understory had low mean symmetry, while it was higher for both midstory and understory with no significant differences between the latter two canopy levels (Fig. 1). For different dispersal mode groups, wind-dispersed species had the highest similarity followed by gravity-dispersed species and animal-dispersed species. Dry-fruited species showed higher similarity in richness than the fleshy-fruited species (Fig. 1).

Seed abundance was best described by tree traits (Tables S3-S6 in Appendix), and this result was consistent for every functional group (Figs. 2, 3). In particular, the sum of the relative basal area appeared in all of the $90 \%$ confidence sets of models for the functional groups (Tables S3-S6 in Appendix), and it consistently had a strong explanatory power and a positive influence on seed abundance for all three functional groups (Figs. 2, 3). Tree abundance occurred in

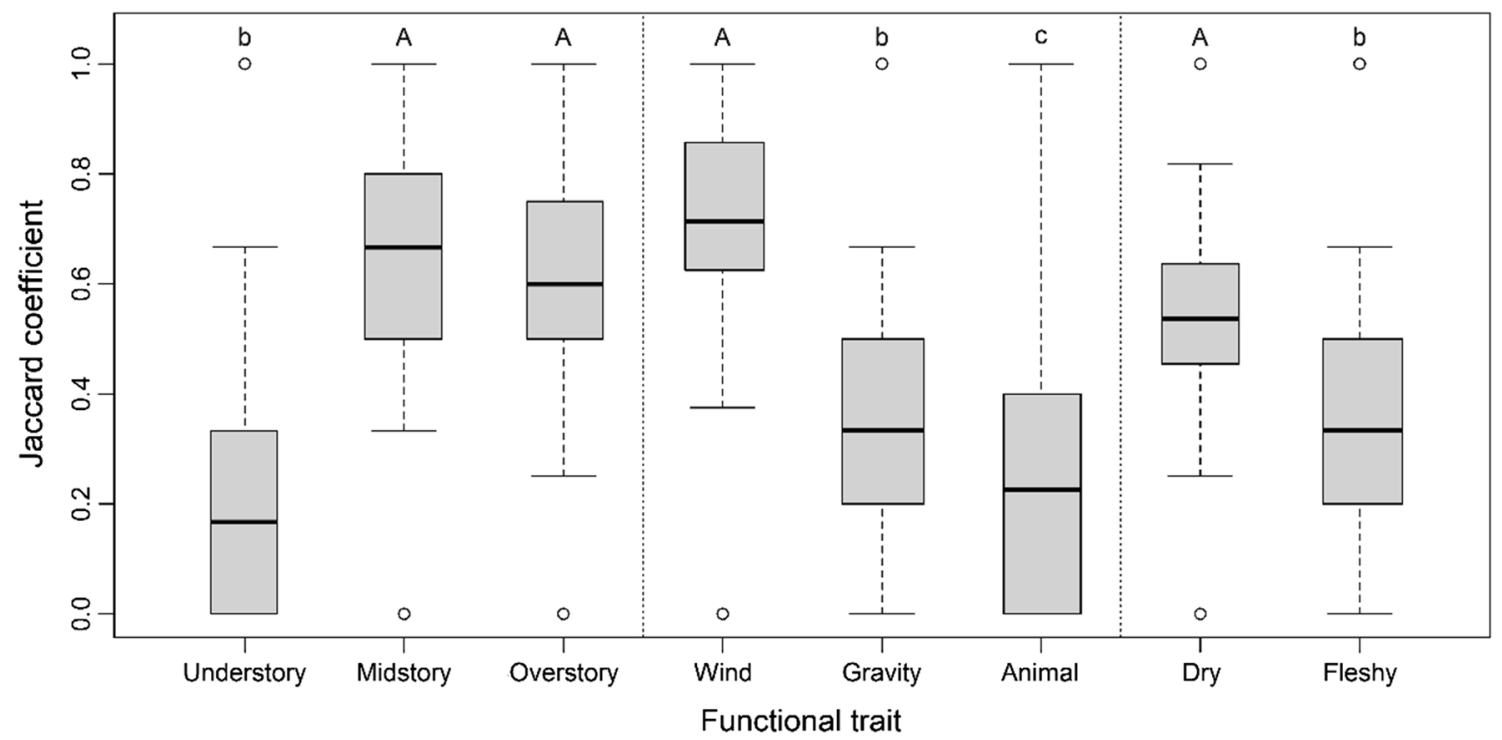

Fig. 1 The Jaccard similarity coefficient between the seed community and neighbouring tree community in each functional group on the trap level, (left to right: canopy levels, dispersal modes, and fruit types). Uppercase letters denote significance (the significant difference among traits within a functional group) at 0.001 level $(99.9 \%)$, lower case at 0.05 level $(95 \%)$ 

seed abundance of midstory and overstory based on the $90 \%$ confidence model sets (Tables S2, S3 in Appendix). Circles show odds ratios for each parameter, with $95 \%$ confidence limits (CL) indicated by horizontal lines. Odds ratios significantly different from 1 (95\% CL do not overlap 1) are indicated by solid circles. Lack of odds ratio in some functional models is because samples were limited and contrasts in models can be applied only to factors with 2 or more levels
Fig. 2 Parameter estimates for
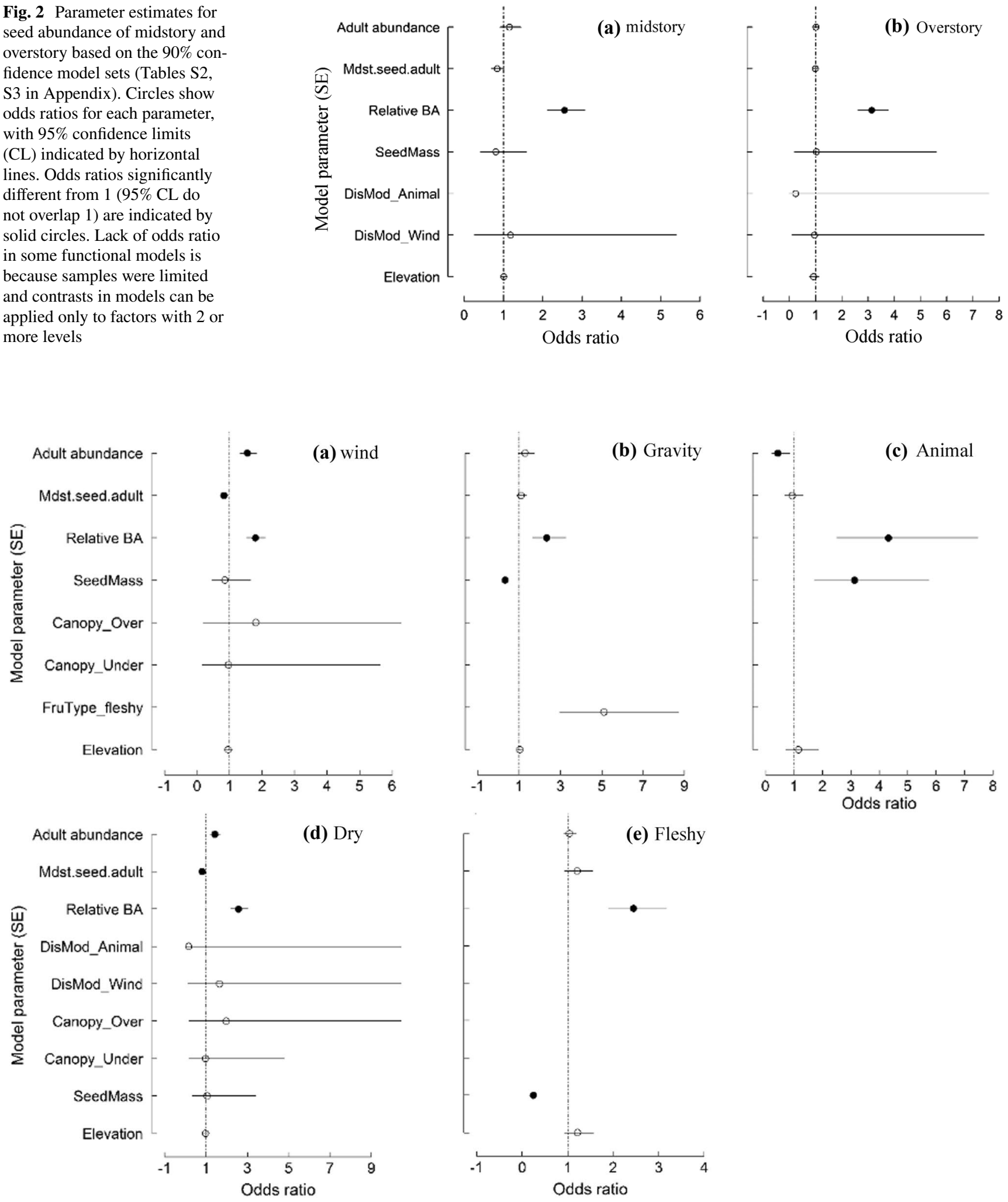

Fig. 3 Parameter estimates for seed abundance among dispersalmode and fruit-type groups based on the $90 \%$ confidence model sets (Tables S4, S5 in Appendix). Circles show odds ratios for each parameter, with $95 \%$ confidence limits (CL) indicated by horizon- tal lines. Odds ratios significantly different from 1 (95\% CL do not overlap 1) are indicated by solid circles. Lack of odds ratio in some functional models is because the samples were limited and contrasts in models can be applied only to factors with two or more levels 
$66.3 \%$ of the confidence sets of models, in particular for the midstory layer (Table S3 in Appendix), dispersal modes (Table S5 in Appendix), and the dry fruit type (Table S6 in Appendix). Model-averaging showed that the 95\% CI for species abundance spanned 1.0 for the canopy layer (Fig. 2) and for gravity-dispersed species and fleshy-fruited species (Fig. 3), while there was a positive effect on seed abundance based on abundance of wind-dispersed and dry-fruited species (Fig. 3). In contrast, seed mass had only a limited effect on seed dispersal for most functional groups, with negative effects on gravity-dispersed and fleshy-fruited species and a positive effect on animal-dispersed species (Fig. 3; Tables S5, S6 in Appendix). Similarly, the dispersal mode also showed only weak effects on seed primary dispersal for all groups (Figs. 2, 3; Tables S3-S6 in Appendix).

\section{Discussion}

Based on 9 years of seed trap data from a 25-ha old-growth temperate forest, the similarity in species composition between the seed rain and neighbouring tree community varied greatly across functional groups, partially supporting the prediction of dispersal limitation. At the community level, some species had strong dispersal limitations, while other species were abundant in both seeds and tree populations and had relatively weak dispersal limitations. For each group, the overstory, wind-dispersed, and dry-fruited species had a higher similarity in species richness and composition between seed deposition and the surrounding tree community than did the other level(s) for each functional group. This study revealed that, for all functional groups, tree traits, especially total relative basal area, contributed more to seed deposition patterns than did the effects of diaspore traits (e.g., fruit and seed traits).

\section{Similarity in species composition on a community level}

All the species represented in the seed traps matched with neighbouring trees. However, a poor match was found between resident trees and the seed rain community; only about half of the species in the plot were represented in the seed traps, a result similar to that of Hardesty and Parker (2003) for tropical forests. Regarding abundance, seed abundance was related to tree abundance in agreement with the results of Lin et al. (2011), but was contrary to Hardesty and Parker (2003) who found no relationship between seed abundance and tree species abundance. The latter study took place in tropical forests where there were a number of animal-dispersed species outside the plot that contributed to the seed rain (see also Drake 1998). In both this temperate CBS and the subtropical Kenting forests (Taiwan island), the relative abundance of tree species was highly uneven with a few dominant species while most were scattered (Hao et al. 2007; Wang et al. 2014). In contrast, in the Hardesty and Parker (2003) study, only species with DBH $>10 \mathrm{~cm}$ were studied, and lianas and shrubs were excluded. It is also noteworthy that both Lin et al. (2011) and Hardesty and Parker (2003) studies were only 1 year long, too brief to account for the high interannual variation in seed production, i.e., the mast seeding strategy, found in many forest regions (Norden et al. 2007; Xiao et al. 2013). Our 9-year data set provided a more reliable estimate of seed abundance because it was an average over both low-fruiting periods and sudden high-fruiting events. The results here show that the species richness and abundance of the seed community was more similar to those of the neighbouring tree community than found in tropical forests.

Both diaspore and tree traits influence seed deposition primarily at the neighbourhood scale (Schupp et al. 2002; Russo and Augspurger 2004; Kwit et al. 2007; Augspurger et al. 2016). Dispersal limitation, a widespread phenomenon across forest communities, reflects local dispersal events, with most seed falling beneath or near parent plants (Janzen 1970; Connell 1971; Clark et al. 1998; Nathan and MullerLandau 2000). For example, both gravity- and wind-dispersed seeds are dispersed around the parent tree, especially those that are gravity-dispersed, while animal-dispersed seeds are more likely to be scattered over relatively long distances (Seidler and Plotkin 2006; Réjou-Méchain et al. 2011). In temperate forests, many tree species are winddispersed (Wang et al. 2014), whereas only a few species are dispersed long distances by animals compared to the case in tropical forests (Howe and Smallwood 1982; Nathan and Muller-Landau 2000). Thus, while a greater similarity between the seed rain community and neighbouring trees may be expected in temperate forests compared to tropical forests, the similarity may still be poor.

\section{Dispersal limitation between levels of functional groups}

The overstory species had the least dispersal limitation, while understory species had the strongest dispersal limitation, as predicted. Seeds of overstory individuals can be dispersed farther than those of mid-layer species because of the positive relationship between tree height and dispersal distance (Muller-Landau et al. 2008; Thomson 2011; Li et al. 2012). In contrast, the understory consists of relatively short-statured shrubs (3-5 $\mathrm{m}$ ) in the temperate mixed forest (Liu et al. 2008), and seeds have lower heights to fall and accordingly would not be dispersed far.

Wind-dispersed species found in traps accounted for the largest proportion of the mature tree community compared to both gravity- and animal-dispersed species (Fig. 1). Similarly, dispersal limitation was much higher in fleshy-fruited species than for dry-fruited species. Animal-dispersed 
species were more widely distributed across the community compared to species that did not have animal dispersal assistance as reported here and from a 50-ha permanent plot study (Seidler and Plotkin 2006), leading to lower consistency between predator-dispersed seed and mature tree communities. Gravity-dispersed species can only release their seeds in a very narrow area around the parent trees (Janzen 1970); hence, seed traps in the center of each sampling circle may be less likely to have gravity-dispersed seeds. Thus, gravity-dispersed species had greater seed dispersal limitations than the wind-dispersed species did.

\section{The relative contribution between diaspore and mature tree traits}

Seed abundance was positively influenced by the relative basal area of trees in all cases analyzed, and abundance in two-thirds of the models, while it was only weakly related to diaspore traits, including seed mass, dispersal mode, and fruit type. This study showed that seed abundance responded more strongly to the traits of neighbouring trees than to the functional traits of diaspores. These results support the predictions of Greene and Johnson (1994) and Augspurger et al. (2016) that tree traits, and not diaspore traits, explain seed dispersal patterns. Augspurger et al. (2016) conducted a study of seed deposition patterns in three environments (still air, a simulated field experiment, and natural field conditions), and found that tree traits, including size/height or canopy layer, and fecundity (relative basal area here), were key factors influencing seed dispersal patterns (Norghauer et al. 2011)

\section{Caveats}

This study was based at the community level, and seed traps were set less than $31 \mathrm{~m}$ from trees. However, one limitation of this study was that the extent of seed shadows of individual trees was unknown. As such, further field observations and analysis of the relationships between the extent of seed shadows and tree traits would benefit the understanding of seed dispersal ecology. Additionally, for animal-dispersed seeds, the species captured by the traps could be underrepresented because it is difficult to identify the roles of preand post-dispersal seed predators on seeds collected in the traps (Forget et al. 1999; Wenny 2001; Chimera 2004; Xu et al. 2015). The effect of predators might thus explain the unexpected, slightly negative effect of tree numbers on seed abundance for animal-dispersed species (Fig. 3). Nonetheless, especially for temperate forests, a relatively regular arrangement of seed traps, as used in this study, may better represent the mature community structure than a trailbased layout confined to aggregated areas within a small region as used in other forest plots, (e.g., SCBI [Smithsonian
Conservation Biology Institute] plot in VA, USA; see Table S7). Therefore, we believe that this study provides a reasonable approach for investigating community-level sources of variation in seed deposition, at least for temperate forests.

Although these results show that diaspore traits had relatively weaker effects than tree traits on seed dispersal, seed dispersal is a complex ecological process (Wenny 2000). Seed distribution around a parent tree depends on diaspore and tree traits, and surrounding vegetation (Augspurger et al. 2016). Although linear models did not detect interactions in patterns of seed abundance, a variety of factors may interact to create the observed patterns. In this regard, further investigation is needed on the synergistic effects among different factors that influence seed diversity and distribution patterns.

\section{Conclusion}

This study supported findings that tree basal area and stand densities are important functional traits explaining seed deposition patterns in the temperate forests of Northeast China. Previous studies have mainly focused on wind-dispersed species, and our findings extend the generality of tree traits in explaining primary seed dispersals to a community of species with a range of dispersal modes and other attributes such as canopy layers and fruit types. Tree traits have gradually replaced the historical emphasis on phenotypic differences in diaspores, aerodynamic behavior, and physical traits that affect the descent rate of diaspores (Augspurger et al. 2016). Seed dispersal is a complex process, and future work should focus on the relationships between tree traits (basal area, height, age) and fecundity, and the interaction of tree and specific diaspore dispersal patterns. This improved knowledge could facilitate further understanding of subsequent seedling and community dynamics.

Acknowledgements We gratefully thank Baizhang Song and Xichang He for collecting the seed rain data. This study was funded by the National Key Research and Development Program of China (2016YFC0500300), National Natural Science Foundation of China (31570432, 31670632, 41671050), and by NSF Grant DEB-1745496 awarded to JML.

Open Access This article is distributed under the terms of the Creative Commons Attribution 4.0 International License (http://creativeco mmons.org/licenses/by/4.0/), which permits unrestricted use, distribution, and reproduction in any medium, provided you give appropriate credit to the original author(s) and the source, provide a link to the Creative Commons license, and indicate if changes were made. 


\section{References}

Augspurger CK, Franson SE, Cushman KC, Muller-Landau HC (2016) Intraspecific variation in seed dispersal of a neotropical tree and its relationship to fruit and tree traits. Ecol Evol 6:1128-42

Bai XJ, Queenborough SA, Wang XG, Zhang J, Li BH, Yuan ZQ, Xing DL, Lin F, Ye J, Hao ZQ (2012) Effects of local biotic neighbors and habitat heterogeneity on tree and shrub seedling survival in an old-growth temperate forest. Oecologia 170:755-765

Barton K (2016) MuMIn: multi-model inference. R package version 1.15.6. https://CRAN.R-project.org/package=MuMIn

Bates D, Maechler M, Bolker B (2011) lme4: Linear mixed-effects models using S4 classes. https://cran.R-project.org/packa ge $=$ lme 4 . R package version $0.999375-42$

Beaudrot L, Rejmánek M, Marshall AJ (2013) Dispersal modes affect tropical forest assembly across trophic levels. Ecography 36:984-993

Bleher B, Böhning-Gaese K (2001) Consequences of frugivore diversity for seed dispersal, seedling establishment and the spatial pattern of seedlings and trees. Oecologia 129:385-394

Blume JD, Su L, Olveda RM, McGarvey ST (2007) Statistical evidence for GLM regression parameters: a robust likelihood approach. Stat Med 26:2919-2936

Burnham KP, Anderson DR (2004) Multimodel inference: understanding AIC and BIC in model selection. Sociol Methods Res 33:261-304

Chimera CG (2004) Investigating seed dispersal and seed predation in a Hawaiian dry forest community. Unpublished M.Sc. Thesis, University of Hawaii at Manoa, Honolulu, pp 46-62

Clark JS, Beckage B, Camill P, Cleveland B, HilleRisLambers J, Lichter J, McLachlan J, Mohan J, Wyckoff P (1999) Interpreting recruitment limitation in forests. Am J Bot 1:1-16

Clark JS, Macklin E, Leslie W (1998) Stages and spatial scales of recruitment limitation in southern Appalachian forests. Ecol Monogr 68:213-235

Condit R (1998) Tropical forest census plots: Methods and results from Barro Colorado Island, Panama and a comparison with other plots, 211p. Springer, Berlin

Connell JH (1971) On the role of natural enemies in preventing competitive exclusion in some marine animals and in rain forest trees. In: Boer PJ, Gradwell GR (eds.), Dynamics of numbers in populations, pp 298-312. Wageningen, PUDOC

Dalling JW, Muller-Landau HC, Wright SJ, Hubbell SP (2002) Role of dispersal in the recruitment limitation of neotropical pioneer species. J Ecol 90:714-727

Dormann CF, Elith J, Bacher S, Buchmann C, Carl G, Carré G, Marquéz JR, Gruber B, Lafourcade B, Leitão PJ, Münkemüller T (2013) Collinearity: a review of methods to deal with it and a simulation study evaluating their performance. Ecography 36:27-46

Drake DR (1998) Relationships among the seed rain seed bank and vegetation of a Hawaiian forest. J Veg Sci 9:103-112

Dupré C, Ehrlén J (2002) Habitat configuration, species traits and plant distribution. J Ecol 90:796-805

Forget PM, Kitajima K, Foster RB (1999) Pre-and post-dispersal seed predation in Tachigali versicolor (Caesalpiniaceae): effects of timing of fruiting and variation among trees. Journal of Tropical Ecology 15:61-81

Gautier-Hion A, Duplantier JM, Quris R, Feer F, Sourd C, Decoux JP, Dubost G, Emmons L, Erard C, Hecketsweiler P, Moungazi A (1985) Fruit characters as a basis of fruit choice and seed dispersal in a tropical forest vertebrate community. Oecologia 65:324-337

Ghazoul J (2005) Pollen and seed dispersal among dispersed plants. Biol Rev 80:413-443
Greene DF, Johnson EA (1994) Estimating the mean annual seed production of trees. Ecology 75:642-647

Hao ZQ, Zhang J, Song B, Ye J, Li BH (2007) Vertical structure and spatial associations of dominant tree species in an old-growth temperate forest. Forest Ecol Manag 252:1-11

Hardesty BD, Parker VT (2003) Community seed rain patterns and a comparison to adult community structure in a West African tropical forest. Plant Ecol 164:49-64

Harms KE, Wright SJ, Calderon O, Hernandez A, Herre EA (2000) Pervasive density-dependent recruitment enhances seedling diversity in a tropical forest. Nature 404:493-495

Howe HF, Smallwood J (1982) Ecology of seed dispersal. Annu Rev Ecol Evol Syst 13:201-228

Janzen DH (1970) Herbivores and the number of tree species in tropical forests. Am Nat 104:501-528

Jordano P, Forget PM, Lambert JE, Böhning-Gaese K, Traveset A, Wright SJ (2011) Frugivores and seed dispersal: mechanisms and consequences for biodiversity of a key ecological interaction. Biol Lett 7:321-323

Kwit C, Levey DJ, Turner SA, Clark CJ, Poulsen JR (2007) Out of one shadow and into another: causes and consequences of spatially contagious seed dispersal by frugivores. In: Dennis AJ, Schupp EW, Green RJ, Westcott DA (eds.), Seed dispersal: theory and its application in a changing world, pp 427-444. CAB International, Wallingford

Levine JM, Murrell DJ (2003) The community-level consequences of seed dispersal patterns. Annu Rev Ecol Evol Syst 34:549-574

Li BH, Hao Z, Bin Y, Zhang J, Wang M (2012) Seed rain dynamics reveals strong dispersal limitation, different reproductive strategies and responses to climate in a temperate forest in Northeast China. J Veg Sci 23:271-279

Lin YC, Lin PJ, Wang HH, Sun IF (2011) Seed distribution of eleven tree species in a tropical forest in Taiwan. Bot Stud 52:327-336

Liu L, Li JG, Liao HW (2008) Ecological strategies for protection and management in broadleaved Korean pine forest. J Heilongjiang Vocat Inst Ecol Eng 5:42-43

Lorts CM, Briggeman T, Sang T (2008) Evolution of fruit types and seed dispersal: a phylogenetic and ecological snapshot. J Syst Evol 46:396-404

Maron JL, Kauffman MJ (2006) Habitat-specific impacts of multiple consumers on plant population dynamics. Ecology 87:113-124

McHugh ML (2009) The odds ratio: calculation, usage, and interpretation. Biochem Medica 19(2):120-126

Moran C, Catterall CP (2010) Can functional traits predict ecological interactions? A case study using rain forest frugivores and plants in Australia. Biotropica 42:318-326

Muller-Landau HC, Wright SJ, Calderón O, Condit R, Hubbell SP (2008) Interspecific variation in primary seed dispersal in a tropical forest. J Ecol 96:653-667

Nakagawa S, Schielzeth H (2013) A general and simple method for obtaining R2 from generalized linear mixed-effects models. Methods Ecol Evol 4:133-142

Nathan R, Katul GG, Horn HS, Thomas SM, Oren R, Avissar R, Pacala SW, Levin SA (2002) Mechanisms of long-distance dispersal of seeds by wind. Nature 418:409-413

Nathan R, Muller-Landau HC (2000) Spatial patterns of seed dispersal, their determinants and consequences for recruitment. Trends Ecol Evol 15:278-285

Norden N, Chave J, Belbenoit P, Caubère A, Châtelet P, Forget PM, Thébaud C (2007) Mast fruiting is a frequent strategy in woody species of Eastern South America. PLoS One 2:e1079

Norghauer JM, Charles AN, James G (2011) The importance of tree size and fecundity for wind dispersal of big-leaf mahogany. PLoS One 3:e17488 
R Development Core Team (2015) R: A language and environment for statistical computing. https://www.r-project.org/

Réjou-Méchain M, Fayolle A, Nasi R, Gourlet-Fleury S, Doucet JL, Gally M, Hubert D, Pasquier A, Billand A (2011) Detecting largescale diversity patterns in tropical trees: can we trust commercial forest inventories? Forest Ecol Manag 261:187-194

Ribbens E, Silander JA, Pacala SW (1994) Seedling recruitment in forests: calibrating models to predict patterns of tree seedling dispersion. Ecology 75:1794-1806

Russo SE, Augspurger CK (2004) Aggregated seed dispersal by spider monkeys limits recruitment to clumped patterns in Virola calophylla. Ecol Lett 7:1058-1067

Ruxton GD, Schaefer HM (2012) The conservation physiology of seed dispersal. Philos Trans R Soc B. 367:1708-18

Schielzeth H (2010) Simple means to improve the interpretability of regression coefficients. Methods Ecol Evol 1:103-113

Schupp EW, Milleron T, Russo SE (2002) Dissemination limitation and the origin and maintenance of species-rich tropical forests. In: Levey DJ, Silva WR, Galetti M (eds) Seed dispersal and frugivory: ecology, evolution, and conservation. CABI Publishing, New York, pp 19-34

Schurr FM, Steinitz O, Nathan R (2008) Plant fecundity and seed dispersal in spatially heterogeneous environments: models, mechanisms and estimation. J Ecol 96:628-641

Seidler TG, Plotkin JB (2006) Seed dispersal and spatial pattern in tropical trees. PLoS Biol 4:e344

Shen ZH, Lü N, Zhao J (2004) The topographic pattern of seed rain of a mountain mixed evergreen and deciduous forest community. Chin Acta. Theriol Sin 24:1981-1987 (in Chinese with English abstract)

Thomson FJ, Moles AT, Auld TD, Kingsford RT (2011) Seed dispersal distance is more strongly correlated with plant height than with seed mass. J Ecol 99:1299-1307

Van Der Burgt XM (1997) Explosive seed dispersal of the rainforest tree Tetraberlinia moreliana (Leguminosae-Caesalpinioideae) in Gabon. J Trop Ecol 13:145-151

Wang LW, Li BH, Y J, Bai XJ, Yuan ZQ, Xing DL, Lin F, Shi S, Wang XG, Hao ZQ, (2011) Dynamics of short-term tree mortality in broad-leaved Korean pine (Pinus koraiensis) mixed forest in the Changbai Mountains. Chinese Bio Sci 19:260-270
Wang XG, Ye J, Li BH, Zhang J, Lin F, Hao ZQ (2010) Spatial distributions of species in an old-growth temperate forest, northeastern China. Can J For Res 40:1011-1019

Wang YY, Shi S, Fei L, Yuan ZQ, Ye J, Wand XG, Hao ZQ (2014) Reproductive traits and their correlations among woody plants in a broadleaf-Korean pine (Pinus koraiensis) mixed forest in Northeast China. Chinese Sci Bull 59:2407-2415 (in Chinese with English abstract)

Wenny DG (2001) Advantages of seed dispersal: a re-evaluation of directed dispersal. Evol Ecol Res 3:37-50

Wenny DG (2000) Seed dispersal, seed predation and seedling recruitment of a Neotropical mountain tree. Ecol Monogr 70:331-351

Whittingham MJ, Stephens PA, Bradbury RB, Freckleton RP (2006) Why do we still use stepwise modelling in ecology and behaviour? J Anim Ecol 75:1182-1189

Xiao Z, Zhang Z, Krebs CJ (2013) Long-term seed survival and dispersal dynamics in a rodent-dispersed tree: testing the predator satiation hypothesis and the predator dispersal hypothesis. J Ecol 101:1256-1264

Xu Y, Shen Z, Li D, Guo Q (2015) Pre-Dispersal Seed Predation in a Species-Rich Forest Community: Patterns and the Interplay with Determinants. PloS one 10:e0143040

Yang H, Li D (1985) Distribution patterns of dominant tree species on northern slope of Changbai Mountain. Chin For Ecosyst Res $5: 1-14$

Zhang J, Hao ZQ, Li BH, Y J, Wang XG, Yao XL, (2008) Composition and seasonal dynamics of seed rain in broad-leaved Korean pine (Pinus koraiensis) mixed forest, Changbai Mountain. Chinese Acta Ecol Sin 28:2445-2454 (in Chinese with English abstract)

Zhou BX, Chen YS (2001) Seeds of woody plants in China. China Forestry Publishing House, Beijing, pp 142-1017

Publisher's Note Springer Nature remains neutral with regard to jurisdictional claims in published maps and institutional affiliations. 